\section{Juvenile arthritis disease activity score is a better reflector of active disease than the disease activity score 28 in adults with polyarticular juvenile idiopathic arthritis}

A considerable proportion of children with polyarticular juven-ile idiopathic arthritis (polyJIA) experience active disease into adulthood. ${ }^{1}$ However, there is no validated disease activity measure for adults with polyJIA, and they are often assessed using the disease activity score 28 (DAS28). DAS28 is validated in adults with rheumatoid arthritis (RA), and determines qualification for biological drugs in the UK and other countries. ${ }^{2} 3$ In contrast to the juvenile arthritis disease activity score ( JADAS), ${ }^{4}$ DAS28 does not fully evaluate the pattern of joint involvement often observed in polyJIA. In this study, we compared DAS28 with JADAS-10 in adolescents and adults with polyJIA.

Tender and swollen joint counts out of 28 , active joint count of all joints up to a maximum of 10 , patient/parent and physician global assessment visual analogue scales were collected from clinics in patients aged $\geq 10$ years with polyJIA (International League of Associations for Rheumatology classification criteria for rheumatoid factor-negative (RhF-ve) or rheumatoid factorpositive $(\mathrm{RhF}+\mathrm{ve})$ polyJIA). Erythrocyte sedimentation rate (ESR) values were taken within 30 days before or after assessment. When unavailable, values were taken within 3 months before or after, provided the patient remained stable between the ESR test and assessment. When unavailable within these time periods, patients were excluded from analysis. DAS28 and JADAS-10 were calcu-lated and compared using Spearman's rank correlation coefficient. DAS28 $>5.1$ constitutes high-disease activity in adults with RA, $\leq 3.2$ suggests low-disease activity or remission. $^{23}$ In children with polyJIA, JADAS-10>10.5 is considered to reflect high-disease activity, ${ }^{5} \leq 3.8$ reflects low or inactive disease. $^{67}$

Forty-nine patients ( 36 polyJIA-RhF-ve, 10 polyJIA-RhF+ve, 3 unknown RhF) were analysed (range $=10-27$ years, median $=15$ years, M:F ratio 1:3.5). Good correlation was seen between the disease activity scores (Spearman's $r=0.69, \quad p<0.0001$ ). However, when looking at values above cut-offs defined for active disease, considerable underestimation of disease activity by DAS28 was observed with 13 patients having JADAS-10>10.5 but only 1 of these patients having DAS28>5.1 (figure 1).

There was no considerable difference in correlation between disease activity scores between adolescents (range $=10-15$ years, median $=13$ years, $\mathrm{n}=25$, Spearman's $\mathrm{r}=0.83, \mathrm{p}<0.0001)$ and adults (range $=16-27$ years, median $=17$ years, $n=24$, Spearman's $\mathrm{r}=0.73, \mathrm{p}<0.0001)$, nor between polyJIA-RF-ve

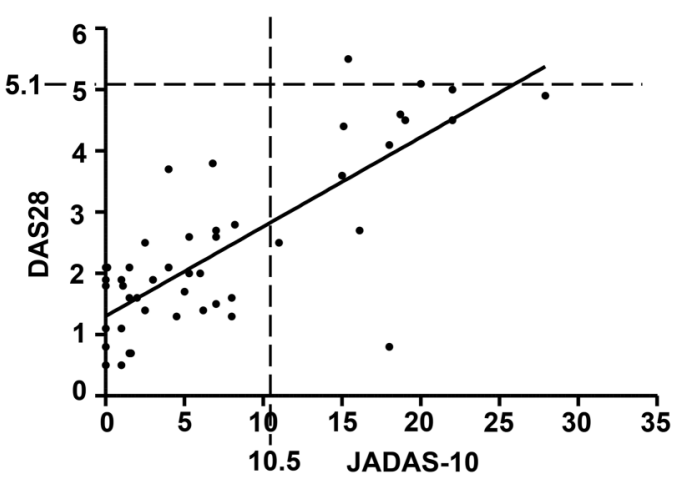

Figure 1 Scatter plot with linear regression line of juvenile arthritis disease activity score 10 (JADAS-10, x-axis) and disease activity score 28 (DAS28, y-axis). Despite good correlation between these disease activity measures, there is a discrepancy in the threshold for high-disease activity between JADAS-10 (JADAS-10 $>10.5$, vertical dotted line) and DAS28 (DAS28 >5.1, horizontal dotted line). Also, 13 out of 49 patients were classified as high-disease activity by JADAS-10 (data points to the right of the vertical dotted line), and of these, only 1 was defined as also being high-disease activity by DAS28 (data point above the horizontal dotted line). No patients were classified as high activity for DAS28 but not high according to JADAS-10.

$(n=36$, Spearman's $r=0.68, p<0.0001)$ and polyJIA-RF+ve $(n=10$, Spearman's $r=0.80, p=0.0088)$.

Although previous studies found good correlations between DAS28 and JADAS in children with $\mathrm{JIA}^{8}{ }^{8}$ this is the first to include the adult population and highlight a discrepancy in thresholds for high-disease activity between DAS28 and JADAS.

Looking at individual patients, 9 out of 10 patients with active disease defined by JADAS (table 1) had joints deemed to be active that are not included in the DAS2 8 joint count, thus contributing to a high JADAS but not affecting DAS28. It would be pertinent to also calculate DAS44, but data were incomplete. If total active joints are greater than DAS28 swollen or tender joints, this could strongly imply JADAS incorporates joints outside those surveyed by DAS28. Seventy-five per cent of patients with active disease defined by JADAS but not DAS28 had higher total active joints than 28 tender or swollen joints compared with $17 \%$ of those patients not classified as active by JADAS and DAS28. This further suggests that a discrepancy in the proportion of patients with active disease as defined by JADAS and DAS28 respectively is predominantly due to differences in the number and distribution of joints surveyed.

In many countries where DAS28 is used in adults with polyarthritis regardless of age of onset, this may have important implications when determining which patients qualify for biological drugs. These data support ongoing use of JADAS as the more appropriate disease activity measure to use in adults with polyJIA. A larger study to determine how this may impact on therapeutic decisions is warranted.

Qiong Wu, ${ }^{1}$ Hema Chaplin, ${ }^{1}$ Nicola Ambrose ${ }^{1,2}$ Debajit Sen ${ }^{1,2}$ Maria J Leandro, ${ }^{2}$ Charlotte Wing, ${ }^{2}$ Nicola Daly, ${ }^{2}$ Kate Webb, ${ }^{1,2}$ Corinne Fisher, ${ }^{1,2}$ Linda Suffield, ${ }^{1}$ 'Francesca Josephs, ${ }^{1}$

Clarissa Pilkington, ${ }^{3}$ Despina Eleftheriou, ${ }^{1}$ Muthana Al-Obaidi, ${ }^{3}$ Sandrine Compeyrot-Lacassagne, ${ }^{3}$ Lucy R Wedderburn, Yiannis loannou ${ }^{1,2}$

${ }^{1}$ Arthritis Research UK Centre for Adolescent Rheumatology, University College London, London, UK

${ }^{2}$ Adolescent Rheumatology Department, University College London Hospital NHS Trust, London, UK

${ }^{3}$ Paediatric Rheumatology Department, Great Ormond Street Hospital for Children NHS Trust, London, UK

${ }^{4}$ Infection, Immunity, Inflammation, and Physiological Medicine Programme, Institute of Child Health, University College London, London, UK 
Table 1 Joint counts in patients with active disease as defined by juvenile arthritis disease activity score-10

\begin{tabular}{|c|c|c|c|c|}
\hline $\begin{array}{l}\text { Patient } \\
\text { code }\end{array}$ & Tender joints & Swollen joints & Active joints & $\begin{array}{l}\mathrm{RF} \\
\text { status }\end{array}$ \\
\hline 13 & L ankle & None & L ankle, L subtalar & $\mathrm{Neg}$ \\
\hline 17 & R knee & $\mathrm{R}$ knee & $\begin{array}{l}R \text { knee, } L \text { ankle, } R \text { ankle, } L \text { subtalar, } \\
R \text { subtalar, } L \text { midfoot, } R \text { midfoot }\end{array}$ & Neg \\
\hline 30 & L TMJ, R TMJ & $\begin{array}{l}\mathrm{L} \text { index } \mathrm{MCP}, \mathrm{R} \text { index } \mathrm{MCP} \\
\mathrm{L} \text { middle } \mathrm{MCP}, \mathrm{R} \text { middle } \mathrm{MCP}\end{array}$ & L TMJ, R TMJ, 2 MCPs & Pos \\
\hline 31 & Unknown & Unknown & Unknown & Neg \\
\hline 33 & $\begin{array}{l}\mathrm{L} \text { wrist, } R \text { wrist, } R \text { middle } M C P \\
L \text { knee, } R \text { knee, } L \text { ankle, } R \text { ankle }\end{array}$ & $\begin{array}{l}\mathrm{L} \text { wrist, } R \text { wrist, } R \text { middle } M C P \\
L \text { knee, } R \text { knee, } L \text { ankle, } R \text { ankle }\end{array}$ & $L$ wrist, $R$ wrist, $R$ middle $M C P, L$ knee, $R$ knee, $L$ ankle, $R$ ankle & Pos \\
\hline 36 & $6 \mathrm{MCPs}, \mathrm{L}$ ankle, $\mathrm{L}$ subtalar & $\begin{array}{l}\text { L elbow, L wrist, } R \text { wrist, } 6 \text { MCPs, } \\
6 \text { PIPs, L ankle, } R \text { ankle, } \\
\text { L subtalar, } R \text { subtalar }\end{array}$ & L elbow, R wrist, 7 MCPs, L ankle, L subtalar & Neg \\
\hline 38 & $\begin{array}{l}\text { L TMJ, R TMJ, L shoulder, L elbow, } \\
5 \text { MCPs, thumb CMC }\end{array}$ & L elbow, thumb CMC, L knee & $\begin{array}{l}\text { L TMJ, R TMJ, L shoulder, L elbow, } 10 \text { MCPs, } \\
\text { L thumb CMC, R thumb CMC, L knee }\end{array}$ & Neg \\
\hline 41 & Unknown & Unknown & Unknown & Pos \\
\hline 44 & $\begin{array}{l}\mathrm{L} \text { shoulder, } R \text { shoulder, } L \text { wrist, } \\
R \text { wrist, } L \text { ring } M C P, R \text { ring } M C P \text {, } \\
L \text { little } M C P, R \text { little } M C P\end{array}$ & $\begin{array}{l}\mathrm{L} \text { ring } M C P, R \text { ring } M C P, \\
L \text { little } M C P, R \text { little } M C P\end{array}$ & $\begin{array}{l}\mathrm{L} \text { shoulder, } R \text { shoulder, } \mathrm{L} \text { wrist, } \mathrm{R} \text { wrist, } \\
\mathrm{L} \text { ring } \mathrm{MCP}, \mathrm{R} \text { ring } M C P, \mathrm{~L} \text { little } M C P, R \text { little } M C P, R \text { hip }\end{array}$ & $\mathrm{Neg}$ \\
\hline 49 & None & Unknown & Unknown & $\mathrm{Neg}$ \\
\hline 50 & $\mathrm{R}$ wrist, $\mathrm{L}$ knee, $\mathrm{L}$ ankle & None & R wrist, $L$ knee, $L$ ankle & $\mathrm{Neg}$ \\
\hline 56 & L TMJ, R TMJ, 2 finger joints & 4 finger joints & L TMJ, R TMJ, 4 finger joints & $\mathrm{Neg}$ \\
\hline 58 & L wrist, R wrist, 9 MCPs, 8 PIPs & L wrist, 10 MCPs, 10 PIPs & L wrist, R wrist, $10 \mathrm{MCPs}, 10$ PIPs & Pos \\
\hline
\end{tabular}

Joints not included within the DAS28 joint count are shown in bold.

CMC, carpometacarpal joint; L, left; MCP, metacarpophalangeal joint; Neg, negative; PIP, proximal interphalangeal joint; Pos, positive; R, right; RF, rheumatoid factor; TMJ, temporomandibular joint.

Correspondence to Dr Yiannis loannou, Arthritis Research UK Centre for Adolescent Rheumatology, University College London, Rayne Institute, 5 University Street, London, WC1E 6JF, UK; y.ioannou@ucl.ac.uk

Acknowledgements The authors thank the patients and staff at the respective departments at Great Ormond Street Hospital and University College London Hospital, and especially Laura Hanns and Chantal Duurland for their help and advice. This article is based on work previously presented as a poster at the 2015 ACR/ARHP Annual Meeting and published as a meeting abstract in September 2015. ${ }^{9}$

Contributors Study conception: YI. Study design: YI and QW. Acquisition of data: $\mathrm{YI}, \mathrm{QW}, \mathrm{HC}, \mathrm{NA}, \mathrm{DS}, \mathrm{MJL}, \mathrm{CW}, \mathrm{ND}, \mathrm{KW}, \mathrm{CF}, \mathrm{LS}, \mathrm{FJ}, \mathrm{CP}, \mathrm{DE}, \mathrm{MA}-\mathrm{O}$, SC-L and LRW. Analysis and interpretation of data: $\mathrm{YI}, \mathrm{LRW}, \mathrm{DS}, \mathrm{NA}$ and QW. Drafting article or revising it critically for important intellectual content: YI, QW, LRW, DS, DE, NA, HC, MJL, CW, ND, KW, CF, LS, FJ, CP, MA-O and SC-L.

Competing interests YI was supported by Arthritis Research UK Grant 20164 and National Institute for Health Research University College London Hospitals Biomedical Research Centre. LRW was supported by Arthritis Research UK Grant 20164, the Great Ormond Street/Institute of Child Health National Institute for Health Biomedical Research Centre and the Medical Research Council Grant MR/ M004600/1. DE was supported by Arthritis Research UK Grant 20164.

Ethics approval This was a service development project given that data were collected as part of routine clinical practice and anonymised for analysis. Institutional ethical approval for this project was obtained.

Provenance and peer review Not commissioned; externally peer reviewed.

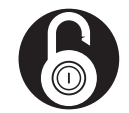

\section{OPEN ACCESS}

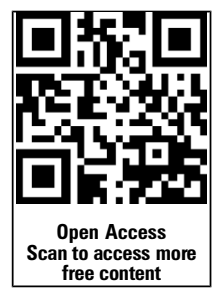

Open Access This is an Open Access article distributed in accordance with the terms of the Creative Commons Attribution (CC BY 4.0) license, which permits others to distribute, remix, adapt and build upon this work, for commercial use, provided the original work is properly cited. See: http://creativecommons.org/ licenses/by/4.0/

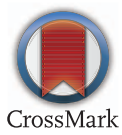

To cite Wu Q, Chaplin H, Ambrose N, et al. Ann Rheum Dis 2016;75:635-636.

Received 24 August 2015

Revised 23 November 2015

Accepted 24 November 2015

Published Online First 29 December 2015

Ann Rheum Dis 2016;75:635-636. doi:10.1136/annrheumdis-2015-208462

\section{REFERENCES}

1 Oen $\mathrm{K}$, Malleson PN, Cabral DA, et al. Disease course and outcome of juvenile rheumatoid arthritis in a multicenter cohort. J Rheumatol 2002;29:1989-99.

2 Prevoo ML, Van't Hof MA, Kuper HH, et al. Modified disease activity scores that include twenty-eight-joint counts. Development and validation in a prospective longitudinal study of patients with rheumatoid arthritis. Arthritis Rheum 1995;38:44-8.

3 Van Gestel AM, Haagsma CJ, Van Riel PL. Validation of rheumatoid arthritis improvement criteria that include simplified joint counts. Arthritis Rheum 1998;41:1845-50.

4 Consolaro A, Ruperto N, Bazso A, et al. Development and validation of a composite disease activity score for juvenile idiopathic arthritis. Arthritis Rheum 2009;61:658-66.

5 Consolaro A, Ruperto N, Bracciolini G, et al. Defining criteria for high disease activity in juvenile idiopathic arthritis based on the juvenile arthritis disease activity score. Ann Rheum Dis 2014;73:1380-3.

6 Consolaro A, Bracciolini G, Ruperto N, et al. Remission, minimal disease activity, and acceptable symptom state in juvenile idiopathic arthritis: defining criteria based on the juvenile arthritis disease activity score. Arthritis Rheum 2012;64:2366-74.

7 Consolaro A, Calandra S, Robbiano C, et al. Treating Juvenile idiopathic arthritis according to JADAS-based targets. Ann Paediatr Rheumatol 2014;3:4-10.

8 Capela RC, Corrente JE, Magalhães CS. Comparison of the disease activity score-28 and juvenile arthritis disease activity score in the juvenile idiopathic arthritis. Rev Bras Reumatol 2015:55:31-6.

9 Wu $Q$, Ambrose $N$, Sen $D$, et al. The Juvenile arthritis disease activity score remains the disease activity marker of choice for adults with polyarticular juvenile idiopathic arthritis. Arthritis Rheumatol 2015;67(Suppl 10):2453-4. 